\title{
User-dependence of myocardial infarct identification using semi-automated thresholding techniques: implications for CRT response predictions based on scar burden
}

\author{
Jonathan Suever ${ }^{1 *}$, Matthew Janick², Stamatios Lerakis², John Oshinski \\ From 2011 SCMR/Euro CMR Joint Scientific Sessions \\ Nice, France. 3-6 February 2011
}

\section{Objective}

To assess the effect of inter-observer variability on myocardial infarct identification and quantification for the prediction of response to CRT.

\section{Background}

Semi-automatic segmentation of infarcted tissue in late gadolinium-enhanced (LGE) MR images is usually done using a thresholding technique. In the threshold technique, an observer identifies a region of remote "normal" myocardium. Based on the distribution of pixel intensities within this "normal" region, pixels that lay more than two standard deviations outside the mean of this distribution are classified as infarcted myocardium.

Having a left ventricular scar burden greater than 33\% has previously been used as a cut-off for predicting nonresponse to cardiac resynchronization therapy (CRT) (Chalil et al. Europace, 2007).

We hypothesized that the user-defined region of "normal" myocardium would have a significant effect on the classification of patients as non-responders to CRT ( $>33 \%$ LV scar burden).

\section{Methods}

On a stack of short-axis LGE images from 22 patients with myocardial scar tissue present, two experienced observers manually traced: 1) endocardial and epicardial borders, and 2) a region of nulled (normal) myocardium. For each user, the mean and standard deviation of pixel intensities within the "normal" ROI were computed. Any pixel within the myocardium at least two standard deviations above this mean was classified as infarct. Using these values, scar burden estimates (\% LV mass) were compared.

The two observers' classification of each patient as a responder or non-responder was compared using Cohen's kappa $(\kappa)$, a measure of agreement of categorical measures.

\section{Results}

When applying the $33 \%$ scar burden cutoff to the automatically segmented scar, the predicted response rates were $33 \%$ for observer 1 and $73 \%$ for observer 2 . The observers agreed on the selection of non-responders only $60 \%$ of the time $(\kappa=0.3)$ indicating poor agreement.

The discrepancy in response prediction can be partly attributed to the low correlation between the two observers using the automated method. A large inter-observer variation makes it difficult to reliably use a threshold for CRT response predication that is obtained using threshold methods for scar identification.

\section{Conclusion}

Scar estimates relying upon threshold-based identification techniques are highly operator dependent. To use LGE scar burden values to select patients for CRT, a manual infarct border should be used, or more reliable infarct identification techniques must be developed for clinical use. 


\section{Author details}

${ }^{1}$ Georgia Institute of Technology/Emory University, Atlanta, GA, USA.

${ }^{2}$ Department of Cardiology, Emory University School of Medicine, Atlanta, GA, USA. ${ }^{3}$ Department of Radiology, Emory University School of Medicine, Atlanta, GA, USA.

Published: 2 February 2011

doi:10.1186/1532-429X-13-S1-P263

Cite this article as: Suever et al:: User-dependence of myocardial infarct identification using semi-automated thresholding techniques:

implications for CRT response predictions based on scar burden. Journal of Cardiovascular Magnetic Resonance 2011 13(Suppl 1):P263.

Submit your next manuscript to BioMed Central and take full advantage of:

- Convenient online submission

- Thorough peer review

- No space constraints or color figure charges

- Immediate publication on acceptance

- Inclusion in PubMed, CAS, Scopus and Google Scholar

- Research which is freely available for redistribution

Submit your manuscript at www.biomedcentral.com/submit
C Biomed Central 